\title{
JUAN RULFO Y LA LITERATURA BRASILEÑA ENTREVISTA CON DANIEL SADA
}

Rodolfo Mata

Publicamos aquí una entrevista inédita con el poeta y novelista mexicano Daniel Sada (1953-2011), autor de Porque parece mentira la verdad nunca se sabe, Casi nunca, La duración de los empeños simples y Aquí, entre otros. La entrevista, concedida al profesor y escritor mexicano Rodolfo Mata en la Ciudad de México en 2003, relata principalmente observaciones de Juan Rulfo, en conversaciones con Sada, sobre literatura brasileña, en particular sobre João Guimarães Rosa, con quien el autor de Pedro Páramo convivió en los años 1960 .

Rodolfo Mata: Daniel, con agrado recuerdo la sorpresa que me llevé cuando, al conversar contigo sobre literatura brasileña, hace ya varios años, me dijiste que conocías y admirabas la obra de João Guimarães Rosa. Aún mayor fue mi interés después de que me contaste que había sido Juan Rulfo quien te había recomendado su lectura.

Daniel Sada: Te voy a repetir lo que él me dijo. Yo fui becario becario del Centro Mexicano de Escritores de 1979 a 1980. Fue entonces que conocí a Juan Rulfo. Más o menos nos hicimos amigos. Íbamos de vez en cuando a tomar un café. También yo lo visitaba mucho ahí en Casa del Lago y así fue como me empezó a platicar de Guimarães Rosa.

RM: ¿Y fue exclusivamente de Guimarães Rosa o te habló de la literatura brasileña en general?

DS: No, me habló también de Machado de Assis, Graciliano Ramos, Rubem Fonseca y Jorge Amado, aunque Jorge Amado no le gustaba.

RM: Es verdad, en una de las entrevistas que revisé — que están dispersas en lo que toca a este tema- Rulfo dice que Jorge Amado era como Luis Spota.

DS: Decía que era demasiado costumbrista y que eso llegaba a aburrirle un poco sobre todo en novelas tan largas. En los cuentos más o menos lo apreciaba, pero de las novelas decía que eran muy largas, que le desesperaban mucho, especialmente esto de las costumbres, de rescatar lo insólito de las costumbres. No le interesaba. Decía que si Amado escribiera más corto tal vez sí le hubiera llamado la atención.

RM: ¿Y estos comentarios Rulfo los hacía en las sesiones del Centro Mexicano de Escritores, o nada mas te los hacía a ti? 
DS: Sólo a mí porque también me gustaba la literatura brasileña y siempre me ha gustado.

RM: ¿Tú ya conocías desde antes la literatura brasileña?

DS: A Guimarães Rosa, poco, pero conocía a Machado de Assis muy bien, a Clarice Lispector. Antes de platicar con Rulfo ya tenía conocimiento sobre todo de poetas: Carlos Drummond de Andrade, Vinicius de Moraes, João Cabral de Neto, Murilo Mendes y Manuel Bandeira. Después empecé a leer narrativa, poco a poco.

RM: Entonces fue como una afinidad con Rulfo.

DS: Sí, era un tema que compartíamos. Me habló mucho de Guimarães Rosa. Consideraba que Gran Sertón: veredas era la mejor novela del siglo XX y lo sostuvo hasta que murió.

RM: ¿Y qué razones te daba?

DS: Decía que había transformado el idioma, que daba una visión muy especial de la región de Minas Gerais en que sucede. Según Rulfo, Gran Sertón: veredas había aportado muchas novedades no sólo al portugués sino a otras lenguas, a través de las traducciones. Transmitía una visión fantástica, como si se tratara de otro mundo, y al mismo tiempo, lo hacía con una mezcla de candor y malicia que le interesaba mucho.

RM: Entonces Rulfo percibía que esta mezcla de candor y malicia era un rasgo de Guimarães Rosa.

DS: Sí. Era muy audaz en su expresión. Siempre había como el candor del campesino pero la malicia del escritor, del narrador. Rulfo decía que para él fue un gran aprendizaje leer a Guimarães.

RM: ¿Rulfo leía en portugués?

SD: No sé, no sé, sabía algo de portugués, pero no sé si pudiese leer a Guimarães en portugués.

RM: Me parece difícil, lo digo porque incluso es difícil para los propios brasileños. Sin embargo, la traducción de Ángel Crespo de Gran Sertón: veredas salió a la luz en 1967. En marzo de ese año Guimarães Rosa vino a México — ambos escritores ya se conocían desde antes- y en noviembre murió. Entonces lo más probable es que lo haya leído auxiliándose de las traducciones al inglés, francés y alemán, que salieron antes.

DS: Quizás, nunca me dijo.

RM: ¿Qué otros libros te recomendó?

DS: Me recomendó Angustia de Garciliano Ramos, El caso Morel de Rubem Fonseca, La hora de la estrella de Clarice Lispector, y todo, todo Machado de Assis, a quien admiraba muchísimo. 
RM: Algunas obras de Machado de Assis ya estaban traducidas pero otras no. Seguramente leyó parte en portugués. La prosa machadiana no tiene las complicaciones lingüísticas que tiene Gran Sertón: veredas.

DS: Rulfo leyó la famosa Memorias Póstumas de Blas Cubas, leyó Quincas Borba, me habló de "El Alienista" y de otros cuentos.

RM: La traducción que hizo Antonio Alatorre de Memorias Póstumas de Blas Cubas, publicada por el Fondo de Cultura Económica en 1951, fue reeditada después en la colección "Clásicos Americanos", SEP-UNAM, acompañada de un prólogo que escribió Rulfo.

DS: Rulfo me habló también de otros escritores brasileños que yo no conozco a la fecha.

RM: En las entrevistas que he leído menciona, entre otros, a Dalton Trevisan, Adonias Filho y Raquel de Queirós.

DS: Conozco a Dalton Trevisan pero a Adonias Filho y a Raquel de Queirós no.

RM: Cuéntame ahora la anécdota del viaje que hicieron juntos Guimarães y Rulfo por México y cómo fue que se conocieron personalmente.

DS: Rulfo fue primero a Brasil. Me dijo que le había escrito. Me contó que era muy difícil ver a Guimarães, que era un diplomático que estaba encargado de la demarcación de fronteras del territorio brasileño y que para conseguir una cita con él, tardaba hasta 2 o 3 semanas en recibir a la gente. $\mathrm{O}$ sea, no quería que lo molestaran y nunca estaba para nadie. Cuando Rulfo fue a Brasil, le habló y se presentó con la secretaria, porque había que presentarse con la secretaria, no nada mas hablar por teléfono, tenía que ir a la oficina a ver si lo recibían. No hacía citas por teléfono y no recibía a nadie sin que antes lo viera personalmente la secretaria. Guimarães era un hombre muy raro, muy especial. Rulfo me contó que aquella vez que fue, antes que él había llegado una delegación cubana. Sin embargo, a Rulfo lo recibió inmediatamente. Guimarães admiraba muchísimo a Rulfo. A todo mundo le daba largas pero a él tan pronto como llegó lo recibió, incluso lo pasó porque estaba ocupado con los de la delegación cubana. De esto Rulfo contaba una anécdota muy especial. Los cubanos le dijeron: "¿Ya leyó usted Paradiso de Lezama Lima?" Y él les respondió que ya tenía conocimiento de esa novela. "Pues se lo regalamos". Entonces les dijo que tenía conocimiento de la escritura, no de Paradiso, aunque sí de la poesía y de algunos ensayos de Lezama. Le ofrecieron una edición de lujo de Paradiso que habían llevado, con el propósito de obsequiársela, y Guimarães Rosa, así muy diplomático, les dijo: "No, muchas gracias, mejor dénselo a otra persona..."

RM: No le interesaba.

DS: No le interesaba en absoluto, y eso fue delante de Rulfo. Después se vieron, platicaron, no me dijo de qué, pero después de ese viaje que Rulfo hizo a Brasil, como a los dos meses, Guimarães vino a México. Le pidió a Rulfo que él quería conocer las Pirámides de Teotihuacán, y hacer un viaje por el interior de México, en camión de segunda clase, así de esos que ranchean, que andan de pueblo en pueblo. 
RM: En guajolotero.

DS: Sí, en guajolotero. Y se fueron por Guanajuato, Michoacán y Jalisco, y pernoctaban en hoteles pueblerinos. Anduvieron como dos semanas puebleando, y luego ya lo llevó a la parte final, que fue la visita a las pirámides de Teotihuacán. Todo lo hizo Rulfo como anfitrión, no se valió de otra persona, no iba nadie más. Usaron su coche, lo dejaron en un lugar, hicieron todo el periplo, regresaron a recoger el coche, y fueron a Teotihuacán. Luego ya lo llevó de regreso al aeropuerto.

RM: Y mientras tanto tuvo lugar aquel II Congreso Latinoamericano de Escritores que se celebró del 15 al 21 de marzo de 1967. Me parece que se fueron a asomar al congreso, ¿no?

DS: No, que yo sepa no. Es más, creo que no hubo ningún congreso, porque si se hubieran enterado que Guimarães Rosa estaba aquí, inmediatamente hubieran enviado a la prensa, y él no quería nada de eso, había pedido que por ningún motivo lo molestaran. Guimarães decía que había conocido México a través de los libros de Rulfo y que ése era el México que quería conocer, aparte de las pirámides, porque había leído mucho sobre ellas, sobre las culturas prehispánicas, sobre los aztecas y todo aquello.

RM: Sí, en el legendario libro de poemas Magma, ganador de un concurso en 1939 pero publicado sólo en 1996, Guimarães Rosa dice en las primeras líneas de un poema: " Cangrejo sucio / disconforme, / como um compacto Buda violáceo / o un ídolo azteca..." Por otra parte, Guimarães Rosa tenía intereses esotéricos. Quizá eso tenga algo que ver con la visita a Teotihuacán.

DS: Él tenía información sobre las pirámides, Rulfo me contó que sabía mucho acerca de ellas.

RM: Te comentaba que hace tiempo anduve buscando información acerca de la visita de Guimarães Rosa a México y encontré que había venido para el congreso que mencioné. Incluso escribió el texto "Emoción del Brasil", que leyó en Guanajuato, como vicepresidente de dicho congreso, cargo que compartía con Miguel Ángel Asturias.

DS: Rulfo no me especificó en que año hizo ese viaje con Guimarães Rosa pero me imagino que fue en los años sesentas. Porque Rulfo fue conocido internacionalmente alrededor de 1962, o sea, como 6 ó 7 años después de publicar sus libros. En un principio, Pedro Páramo y El llano en llamas tuvieron críticas negativas. Rulfo me contó que la primera edición de mil ejemplares de Pedro Páramo tardó cuatro años en venderse. Era conocido sólo en un pequeño círculo. A partir de que Mariana Frenk tradujo a Rulfo al alemán se inició su fama internacional y su reconocimiento en América Latina.

RM: Y Guimarães Rosa sabía alemán.

DS: Sí, sí.

RM: Estaba pensando cómo conocería Guimarães Rosa la obra de Rulfo, porque esa también es una pregunta importante para saber cuándo se identificaron uno al otro en el panorama de la literatura latinoamericana. 
DS: Parece ser, pero créeme la mitad, que se conocieron en un Congreso Internacional, en algo así como un Congreso Latinoamericano, no sé donde. Inmediatamente hicieron amistad y se leyeron mutuamente. Rulfo hablaba muy bien de él, porque Rulfo hablaba muy mal de casi todos los escritores.

RM: Yo llegue a sospechar, después de leer varias entrevistas, que, como la literatura brasileña no se conocía muy bien - y sigue siendo, en gran medida, ignorada - Rulfo abordaba el tema para despistar a los periodistas reclamando de esta lamentable situación. Como los entrevistadores no sabían nada del asunto, no lo importunaban con preguntas comprometedoras.

DS: Puede ser. Rulfo decía algo, muy curioso de la literatura brasileña. Hacía similitudes con la literatura de Europa del Este. Hay un libro muy famoso que es El pensamiento cautivo de Milosz. Ahí dice una cosa muy especial, dice que los escritores del Este huyeron de las vanguardias, en lo que se refiere a narrativa. $\mathrm{O}$ sea, ni pretendieron crear una vanguardia ni asimilar las vanguardias que venían de Europa Occidental. Era como alejarse un poco del tufo de las vanguardias, pero al mismo tiempo no ser canónicos, no ser obediente a los cambios de la novela del Este, o sea, la novela rusa. Ni vanguardia ni tradición. Intentaron encontrar una vereda entre estas dos fuerzas. Ese fue el planteamiento de Milosz en ese libro. Era difícil pues se trataba de fuerzas que los cercaban. Rulfo decía la literatura brasileña planteaba algo por estilo, o sea, huir de las vanguardias pero tampoco ser canónico.

RM: Ahora que lo comentas, te iba a preguntar acerca de otro tema que aparece recurrentemente en las entrevistas en que toca el tema de la literatura brasileña. Rulfo siempre le echaba tierra a los lacanianos, a la nueva ola, al estructuralismo, decía que habían echado a perder la literatura.

DS: Rulfo hablaba muy mal del estructuralismo y del Noveau Roman. Hablaba mal de Severo Sarduy y de todo este experimentalismo vacuo. No le gustaba Don Segundo Sombra, el Realismo Mágico, Macunaíma, todas esas cosas no le gustaban, o la novela peruana de Ciro Alegría.

RM: ¿Hombres de maíz de Miguel Ángel Asturias?

DS: No, no le decía nada. Si lees los dos libros de Rulfo desde la disyuntiva que mencionaba antes, El llano en llamas es la parte tradicional y, digamos, Pedro Páramo es la parte vanguardista. Son muy distintos.

RM: Te refieres a ese vanguardismo que no es vacuo.

DS: Un vanguardismo que no esta supeditado a la pura experimentación sino que en él hay la elaboración de estructuras muy novedosas. $\mathrm{Y}$ es por eso que le gustaba mucho Guimarães, En Guimarães Rosa, Rulfo veía la tradición y al mismo tiempo la vanguardia, dos fuerzas perfectamente embonadas.

RM: ¿Y hay la posibilidad de que se hayan influido mutuamente, que se hayan leído antes de escribir? Como te decía anteriormente, yo había ubicado la visita de Guimarães Rosa 
en marzo de 1967 pero, por lo que me dices, tal vez hubo otra visita anterior.

DS: Quizá sucedió entre 1962 y 1967. Durante esos cinco años fue cuando Rulfo viajó a Brasil y Guimarães Rosa le correspondió la visita. También Rulfo cuando fue a Brasil fue como de incógnito.

RM: Por las entrevistas supe que viajó en 1974 con la comitiva del presidente Luis Echeverría, y que tuvo contacto con otros escritores brasileños.

DS: El problema de Rulfo cuando viajaba es que no le gustaba ir solo y, como su mujer no quería acompañarlo porque no le gustaban esas cosas, a veces invitaba a un amigo, pero nada mas para que le hiciera compañía. Si iba a viajar a un lugar ya fuera de América Latina o Europa, no iba solo. Era muy tímido, entonces tenía que tener como un interlocutor permanente para sentirse bien en los viajes. Antonio Alatorre viajo mucho con él, alguna vez Arreola, pero sin que ellos fueran invitados, o sea, como sus amigos, nada más. En México sí viaja solo, pero en el extranjero no, algunas veces lo acompaño su hermano, un hermano ganadero que tenía.

RM: ¿Y de Clarice Lispector qué te decía Rulfo?

DS: Le interesaban algunos cuentos, pero no todos. Decía que era una autora desigual.

RM: Me imagino que las novelas eran las que no le gustaban.

DS: Ni los cuentos.

RM: Tal vez veía en ella algo de ese experimentalismo vacuo, que no recompensa al lector.

DS: A mí me gustan mucho los cuentos, pero las novelas se me caen de las manos. Cerca del corazón salvaje me gusta pero sólo un poco. Prefiero a Clarice en los cuentos, en el terreno corto.

RM: ¿Y te has seguido interesando por la literatura brasileña?

DS: Sí, pero no como debiera, porque me gustaría leer portugués y ahí es donde ya lo dudo pues hasta que aprenda... Creo que si te interesa mucho la literatura de un país tienes que aprender el idioma. Y cuando leo ensayo o artículos de revista lo entiendo

RM: A ti te gusta mucho Guimarães Rosa.

DS: Muchísimo. Lo he leído y releído, lo conozco de principio a fin. He conseguido todas las traducciones que hay disponibles. No conozco Ave palabra, de Sagarana sólo algunos cuentos, lo que está traducido. Sagarana no está todo traducido. Pero Menudencia, Tutaméia, lo conozco.

RM: No sabía que existía una traducción completa del libro. Menudencia es una buena aproximación al significado de ese título difícil: Tutaméia.

DS: Ese libro, especialmente ese libro me lo recomendó Rulfo, mucho más que Primeras historias, aunque "Temulento" es un cuento maravilloso. Incluso Rulfo lo reconocía pero 
Menudencia es mejor. Es el más experimental de sus libros. Y no cae en lo vacuo. Es más experimental que Primeras historias y mucho más que Sagarana.

RM: Incluso más experimental que Gran sertón: veredas. Es un libro desafiante pero muy bonito. Me sorprende un poco que le haya llamado tanto la atención a Rulfo siendo una escritura tan radical. Entre los textos que ofrece hay cuentos brevísimos y divagaciones juguetonas en torno al significado de algunas palabras. De cualquier manera me queda claro que una de las características de este libro que Rulfo debe haber apreciado es lo que mencionabas: la habilidad del narrador para mezclar candor y malicia, sabiduría popular y erudición, con audacia formal, experimental.

DS: ¿Guimarães Rosa no es tan conocido como Jorge Amado verdad?

RM: Bueno, no es tan leído como Jorge Amado. Es conocido por fama de nombre, pero que la gente lo lea...

DS: Como Cervantes. Todo mundo habla del Quijote de la Mancha o de Shakespeare pero pocos lo han leído. Me imagino que mucha gente tiene los libros de Guimarães Rosa, los hojea, lee algunas páginas, pero no lee la obra completa.

RM: Gran sertón: veredas es muy conocido en Brasil, pero aquí, créeme, tú eres una de las únicas personas que yo conozco que me ha dicho que es un gran escritor y que su obra le parece fantástica.

DS: Hace dos años se publicó una antología de los relatos de Guimarães Rosa que se llama Campo grande. Yo la presenté en Guadalajara en la Feria del Libro junto con Valquiria Wey. Incluso, le reproché a Valquiria que no hubiera incluido más textos de Menudencias. De Primeras historias casi incluyó todos.

RM: Tal vez son los textos que a ella le gustan.

DS: Sí, creo que son los que a ella le gustan. La parte experimental no le llama mucho la atención.

RM: Regina y yo tradujimos hace ya tiempo textos de Ave palabra y de Tutaméia. ¿Te los pasamos?

DS: Sí, el del lazarillo de un ciego libidinoso y el del tipo que necesitaba ponerle imaginariamente un turbante a un amigo para "exorcizar" su presencia.

RM: Ave palabra es un libro póstumo. Guimarães Rosa no lo dejó terminado y Paulo Rónai lo armó con auxilio de la secretaria del escritor. Podríamos decir que es desigual. Pero Tutaméia sí es muy importante. Ojalá pronto contemos con una edición en México.

DS: Pues eso es lo que yo te podría decir de Guimarães Rosa y de Rulfo.

RM: Muchas gracias por tu tiempo y tu testimonio acerca de un encuentro entre dos grandes escritores, sus gustos y preferencias y tu relación con ellos.

México, DF, noviembre de 2003 